\title{
Chemotherapy induced microsatellite instability and loss of heterozygosity in chromosomes 2, 5 , 10 , and 17 in solid tumor patients
}

\author{
Nasir Kamat ${ }^{1 *}$, Mohammed A Khidhir ${ }^{2}$, Sabir Hussain ${ }^{3}$, Mouied M Alashari ${ }^{4}$ and Ulf Rannug ${ }^{1}$
}

\begin{abstract}
Background: The inevitable side effects of the currently used chemotherapy are associated with serious syndromes. Genotoxic effects and consequent genetic instability may play an important role in these syndromes. The aim of the study was to evaluate chemotherapy-related microsatellite instability (MSI), loss of heterozygosity $(\mathrm{LOH})$, and loss of mismatch repair (MMR) expression in solid tumor patients.
\end{abstract}

Methods: Samples were collected from 117 de novo patients with solid tumors of different origins. Specimens, taken pre- and post-treatment, were screened for MSI and LOH in 10 microsatellite sequences in blood, and expression of five MMR proteins were analyzed in cancer tissues using immunohistochemistry. Statistical analysis included the use of; Fisher's exact test, Chi Square, and an inter-rater reliability test using Cohen's kappa coefficient.

Results: Microsatellite analysis showed that $66.7 \%$ of the patients had MSI, including $23.1 \%$ high-positive MSI and 43.6\% low-positive MSI. A large portion (41\%) of the patients exhibited LOH in addition to MSI. MSI and LOH were detected in seven loci in which incidence rates ranged from 3.8\% positive for Bat-26 to 34.6\% positive for Tp53-Alu. Immunohistochemistry revealed that human mutL homolog 1 (hMLH1) expression was deficient in $29.1 \%$ of the patients, whereas 18.8\%, 23.9\%, 13.4\%, and 9.7\% were deficient for human mutS homolog 2 (hMSH2), P53, human mutS homolog 6 (hMSH6) and human post-meiotic segregation increased 2 (hPMS2), respectively. There was a significant correlation between MSI and LOH incidence in Tp53-Alu, Mfd41, and APC with low or deficient expression of hMLH1, hMSH2, and P53. A significant association between MSI and LOH, and incidence of secondary tumors was also evident.

Conclusions: The negative correlation between MMR expression, MSI, and LOH and increased resistance to anti-cancer drugs and development of secondary cancers demonstrates a useful aid in early detection of potential chemotherapy-related side-effects. The diagnostic value demonstrated in our earlier study on breast cancer patients was confirmed for other solid tumors.

Keyword: Chemotherapy, Genetic instability, Microsatellites, Mismatch repair, Secondary tumors

\section{Background}

Genomic alterations in patients receiving chemotherapy, especially alkylating agents, lead to many abnormal clinical phenotypes. Increased resistance to chemotherapy treatments and generation of secondary cancers, e.g. secondary acute myeloid leukemia (AML) and/or myelodysplasia have been reported with incidence rates of $1-5 \%$

\footnotetext{
* Correspondence: nasir.kamat@su.se

'Department of Molecular Biosciences, the Wenner-Gren Institute (MBW),

Stockholm University, SE-106 91 Stockholm, Sweden

Full list of author information is available at the end of the article
}

[1-4]. Chemotherapy-related AML was described in the 1980s [5,6], followed by a wider range of investigations including all types of cytotoxic agents. In many cancer patients, AML has been detected from a few months to several years after chemotherapy treatment $[2,3,5,7-10]$. Genetic alterations that may be the cause of secondary neoplasms include both germline and somatic mutations, and one or more mechanisms (point mutations, deletions, mitotic recombination, gene conversion, nondisjunction and chromosomal loss, or rearrangement of genes) can be implicated [11-13]. 
Simple tandem repetitive DNA sequences consisting of arrays of one to five base pairs (i.e., microsatellites) have been used as molecular biomarkers in kinship, population genetics, linkage mapping, and other studies [14-17]. These DNA sequences are particularly prone to mutations generating new allele lengths via insertiondeletion loop formation during DNA synthesis [18,19]. Microsatellites can also serve in studying lesions at the gene level, such as duplication or deletion [20,21]. Microsatellite instability (MSI) and loss of heterozygosity $(\mathrm{LOH})$ are frequently described abnormalities known to be some of the early steps in the tumorigenesis pathway [22-24], and correction of MSI and LOH requires sufficient expression and activity of MMR proteins [25]. Genetic alterations are normally corrected by the mismatch repair system (MMR), which employs several proteins including human mutL homolog 1 (hMLH1), human mutS homolog 2, 3 and 6 (hMSH2, hMSH3, and hMSH6, respectively), and human postmeiotic segregation increased1 and 2 (hPMS1 and hPMS2) that are known to interact with P53 protein and tumor suppressor genes [26-28]. Interaction between MMR and tumor suppressor genes is an integral part of repairing damages in microsatellite sequences and reducing potential carcinogenesis in affected patients [29,30]. However, when affected alleles are within tumor suppressor genes, this may lead to loss of function of an active tumor suppressor protein $[31,32]$, which indicates the necessity to assess the genetic alterations within that gene. Moreover, a study conducted in a murine model has demonstrated the trans-generational nature of genotoxic effects of anticancer drugs. The genetic alterations appeared with an increased frequency in germline and somatic cells of the first-generation offspring of the treated animals [33,34]. This trans-generational effect naturally raises concerns about similar genetic instability in children of anticancer therapy survivors.

Treatment-related MSI and LOH have been analyzed in a few studies in recent years, highlighting the importance of screening patients for these genomic instabilities after chemotherapy completion [35-37]. Consequences of MSI and LOH that were observed in these studies included increased resistance to chemotherapy, recurrence of primary tumors, and/or appearance of secondary malignancies. However, these studies were exclusively conducted on breast cancer patients. Investigating the possibility of similar outcomes in patients with other cancers is necessary to determine if this is a more widespread phenomenon.

Following the results reported in our previous study on breast cancer patients [37], a new study was similarly designed to assess whether patients with other solid tumors are predisposed to higher genetic instability linked to chemotherapy treatment. In addition, the present study includes an extended follow-up period of 52 months to verify if it is possible to correlate MSI, LOH, and reduced MMR expression with clinical findings. We believe that such results would point to the existence of a link between chemotherapy-related genetic instability and clinical phenotypes of more chemo-resistant cancers or appearance of secondary tumors.

\section{Results}

\section{Blood samples}

Screening of 10 microsatellite markers revealed that 78 of 117 solid tumor patients $(66.7 \%)$ had microsatellite instability in at least one locus. Based on National Cancer Institute (NCI) criteria, 27 patients (23.1\%) were found to be high-positive MSI (MSI-H) due to MSI and LOH in two or more microsatellites sequences, and 51 patients (43.6\%) exhibited single MSI events and were classified as low-positive MSI (MSI-L). LOH was detected in 48 patients $(41 \%)$. No MSI or LOH was detected in any of the tested markers in 39 patients (33.3\%); this group was classified as microsatellite stable. No MSI or LOH events were detected in the pre-treatment specimens (Table 1). The total incidence of MSI in the blood samples collected was 108/351 (30.7\%). However, the incidence decreased with time. MSI detected in posttreatment specimens was reduced from 78 (66.6\%) in the first to $30(25.4 \%)$ in the second post-treatment samples, and this is compatible with the transient nature of MSI lesions. The number of $\mathrm{LOH}$ events, 48 giving a total of $27.4 \%$, was evenly distributed between the two post-treatment groups (Table 1). Detailed individual incidences of MSI and LOH (Table 2) showed that there was a significant occurrence of these instabilities in five of the seven markers. Tp53-Alu on chromosome 17 was

\begin{tabular}{|c|c|c|c|c|}
\hline Group & $\begin{array}{l}\text { No. of } \\
\text { samples }\end{array}$ & $\begin{array}{l}\text { No. of } \\
\text { MSI- L }\end{array}$ & $\begin{array}{l}\text { No. of } \\
\text { MSI-H }\end{array}$ & $\begin{array}{l}\text { No. of } \\
\mathrm{LOH}\end{array}$ \\
\hline
\end{tabular}

\begin{tabular}{lllll}
\hline Patients & & & & \\
Pre-treatment & 117 & 0 & 0 & 0 \\
Post-treatment 1 & 117 & 51 & 27 & 48 \\
Post-treatment 2 & 117 & 30 & 0 & 48 \\
Reference (healthy) & 60 & 0 & 0 & 0 \\
Pre-treatment & 60 & 2 & 0 & 0 \\
Post-treatment 1 & 60 & 0 & 0 & 0 \\
Post-treatment 2 & & 0 &
\end{tabular}

$\mathrm{LOH}$ at alleles 109 and 118 of APC was accompanied by the appearance of a novel allele of 162 base pairs (see Additional file 1: Figure S1). Furthermore, the incidence rate versus age correlation showed that the incidence of MSI/ $\mathrm{LOH}$ increased with age (see Additional file 2: Figure S2). Cancer-specific incidences of instability showed that pancreatic, lung, and gastric cancer patients had high incidences of MSI (Table 4). 
Table 2 Incidence rate of MSI and LOH, number of alleles isolated, and allelic imbalance noticed for each marker

\begin{tabular}{llllll}
\hline Marker & Chr./Locus & No of positive patients & \% of positive MSI & No. of alleles isolated & Allelic imbalance \\
\hline Mfd15 & $17 q 11.2$ & 15 & $19.2 \%$ & 7 & $L 0-0.69 \cup 1.56-2.72$ \\
APC & $5 q 21 / 22$ & 17 & $21.8 \%$ & 8 & $L 0-0.69 \cup 1.5-2.61$ \\
Tp53-Alu & $17 p 13.1$ & 27 & $34.6 \%$ & 12 & $L 0-0.67 \cup 1.48-2.53$ \\
Mfd41 & $17 p 12-11.1$ & 21 & $26.9 \%$ & 8 & $L 0-0.59 \cup 1.35-2.76$ \\
Bat-25 & $4 q 12$ & 0 & $0 \%$ & 4 & $L 0.71-0.77 \cup 0.94-1.2$ \\
TP53.PCR15 & $17 p 13.1$ & 0 & $0 \%$ & 5 & $L 0.80-0.86 \cup 0.92-1.23$ \\
AFM093xh3 & $2 p 16$ & 11 & $14.1 \%$ & 4 & $L 0-0.68 \cup 1.51-2.44$ \\
Bat-40 & $1 p 13.1$ & 0 & $0 \%$ & 4 & $L 0.73-0.81 \cup 0.91-1.31$ \\
Bat-26 & $2 p$ & 3 & $3.8 \%$ & 5 & $L 0.23-0.62 \cup 1.31-1.65$ \\
Mfd28 & $10 p t e r$ & 7 & $8.9 \%$ & $L 0.2-0.64 \cup 1.37-1.95$ \\
\hline
\end{tabular}

$\mathrm{L}=$ lower allelic imbalance. $\mathrm{U}=$ upper allelic imbalance range.

the marker most susceptible to error; $34.6 \%$ of the positive patients exhibited mutations in this locus. Less frequent but significant incidences of $\mathrm{MSI} / \mathrm{LOH}$ were observed in Mfd41and Mfd15 on chromosome 17, APC on chromosome 5, and AFM093xh3 on chromosome 2 (26.9\%, 19.2\%, 21.8\%, and 14.5\%, respectively, Table 2). Alleles 399 and 402 of Tp53-Alu, allele 157 of Mfd41, allele 198 of AFM093xh3, alleles 147 and 152 of Mfd15, and allele 109 of APC all demonstrated instability and LOH more frequently than other alleles tested (Figure 1). MSI appeared in Tp53-Alu as deletions or insertions of one to a few base pairs, these events occurred with similar frequencies, indicating no inherent preference for one event over the other. $\mathrm{LOH}$ formed the majority of

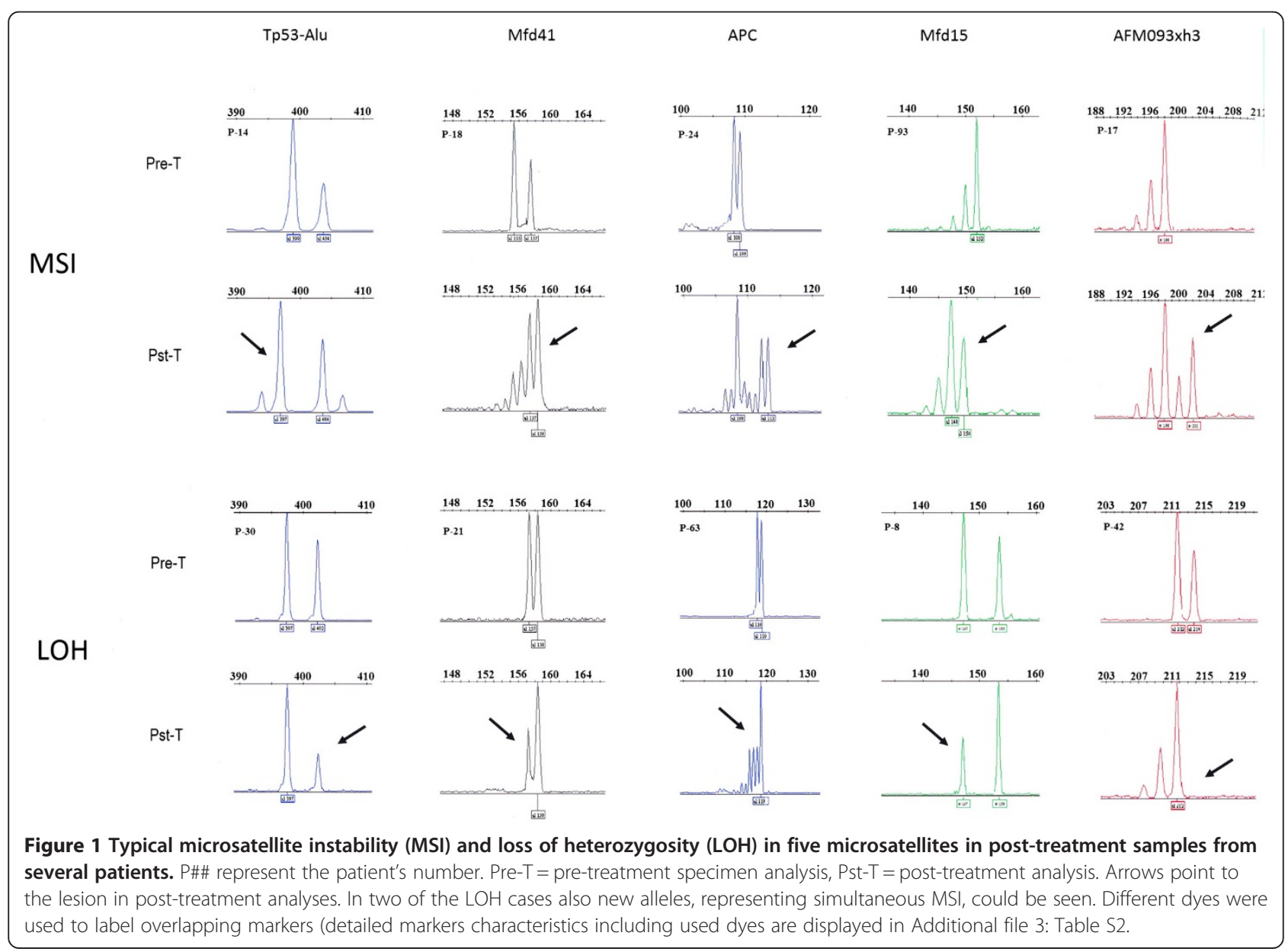


events at this locus, and it most often resulted in nearly $100 \%$ decrease in allele signal. Changes in Mfd41 included shortening of the original allele peak height and the addition of new peaks on both sides of the allele with a higher tendency of deletions (i.e., shorter sequences). LOH in alleles 109 and 118 of APC was accompanied by the emergence of a novel allele of 162 nucleotides (Additional file 1: Figure S1). A reference group of healthy individuals was screened using the same microsatellites panel. The results showed transient MSI-L in two individuals; one in Mfd15 and the other in TP53.PCR15 loci (Table 1). Both transient MSI-L events disappeared in the second samples from the healthy individuals. No $\mathrm{LOH}$ events were detected in the blood samples from the reference group.

\section{Cancer tissues}

Immunohistochemistry demonstrated that chemotherapy treatment induced a loss of expression of MMR proteins. In pre-treatment specimens, hMLH1was deficient in 22 patients (22\%), whereas in post-treatment specimens hMLH1 found to be deficient in 51 patients (51\%), which indicate a loss of expression of this MMR protein in $29 \%$ of cancer tissue $(\mathrm{p}<0.0001)$ after receiving chemotherapy. Furthermore, the pre-treatment specimens showed that hMSH2, P53, hMSH6, and hPMS2 were deficient in 16, 27, 11, and 9 patients, whereas post-treatment specimens were deficient in $35,51,25$, and 19 patients, respectively. These deficiencies accounted for $18.8 \%$ ( $\mathrm{p}<0.0001), 23.9 \%$ ( $\mathrm{p}<0.0001), 13.4 \%(\mathrm{p}=0.0001)$, and $10.2 \%$ ( $\mathrm{p}<0.0001)$ in hMSH2, P53, hMSH6 and hPMS2, respectively.
Statistical analysis showed a significant correlation between low or deficient expression of hMSH2 and MSI/ LOH in Tp53-Alu, Mfd41, and APC (Table 3). Low P53 expression significantly correlated with MSI and $\mathrm{LOH}$ in Tp53-Alu and APC, whereas low or deficient expression of hMLH1 correlated with MSI and LOH in only Tp53Alu (Table 3). Clinical follow-up studies for up to 52 months revealed that 19 patients (16.2\%) were diagnosed with clinical complications of increased resistance to the applied chemotherapy; 15 patients (12.8\%) had a recurrence of primary tumors and 4 patients (3.4\%) developed secondary tumors (Table 4). All 19 complicated cases were patients previously diagnosed to have chemotherapy-related MSI and LOH after the completion of their treatment regimen (13 patients [11.1\%] with MSI-H and 6 [5.1\%] with MSI-L). Fisher's exact test indicated a significant association between MSI/LOH and the incidence of secondary tumors (two-sided Fisher's exact $\mathrm{p}=0.018$, and one-sided Fisher's exact $\mathrm{p}=0.012$ ).

\section{Discussion}

The occurrence of chemotherapy-related genetic instability, especially MSI and LOH, is documented in several studies [38-40]. The importance of studying these instabilities is emphasized by the role MSI and LOH play in the early stages of tumorigenesis and cancer development [22-24]. The assessment of MSI and LOH may carry a predictive value for earlier detection and management of secondary tumors $[37,41]$. Since previous reports indicate that the use of 10 markers is optimal, the present study used a panel of five microsatellites recommended by the NCI guidelines and another five markers

Table 3 Correlation of MSI/LOH incidence to the low expression of MMR genes

\begin{tabular}{|c|c|c|c|c|c|c|}
\hline & & Mfd41 & Tp53-alu & Mfd15 & APC & AFM093xh3 \\
\hline \multirow[t]{3}{*}{ hMLH1 } & Kappa & -0.111 & 0.198 & -0.167 & -0.046 & -0.153 \\
\hline & p-value & 0.212 & 0.031 & 0.041 & 0.587 & 0.078 \\
\hline & Significance Level & Ns & $* *$ & Ns & Ns & Ns \\
\hline \multirow[t]{3}{*}{ hMSH2 } & Kappa & 0.761 & 0.776 & 0.011 & 0.479 & 0.011 \\
\hline & p-value & $<0.0001$ & $<0.0001$ & 0.899 & $<0.0001$ & 0.312 \\
\hline & Significance level & $* * *$ & $* * *$ & Ns & $* * *$ & Ns \\
\hline \multirow[t]{3}{*}{ P53 } & Kappa & 0.139 & 0.559 & -0.145 & 0.213 & -0.125 \\
\hline & p-value & 0.129 & $<0.0001$ & 0.093 & 0.016 & 0.088 \\
\hline & Significance level & Ns & $* * *$ & Ns & $* *$ & Ns \\
\hline \multirow[t]{3}{*}{ hMSH6 } & Kappa & 0.023 & 0.101 & -0.115 & 0.033 & -0.178 \\
\hline & p-value & 0.503 & 0.413 & 0.121 & 0.311 & 0.052 \\
\hline & Significance level & Ns & Ns & Ns & Ns & Ns \\
\hline \multirow[t]{3}{*}{ hPMS2 } & Kappa & 0.142 & -0.206 & -0.162 & 0.086 & -0.107 \\
\hline & p-value & 0.119 & 0.312 & 0.241 & 0.311 & 0.189 \\
\hline & Significance level & Ns & Ns & Ns & Ns & Ns \\
\hline
\end{tabular}

** refers to moderately significant correlation.

*** refers to highly significant correlation. 
Table 4 Cancer types specific results (ratio to the cohort, low and high-positive MSI in each type)

\begin{tabular}{|c|c|c|c|c|c|c|}
\hline Cancer type & No. of cases & $\%:$ study cohort & MSI- L & MSI-H & Recurrence & Secondary CAs \\
\hline Gastric CA & 20 & $17.1 \%$ & 11 & 6 & 4 & 1 \\
\hline Nasopharyngeal CA & 19 & $16.2 \%$ & 6 & 4 & 2 & 1 \\
\hline Ovary CA & 13 & $11.1 \%$ & 5 & 3 & 2 & 0 \\
\hline Lung CA & 12 & $10.3 \%$ & 7 & 3 & 3 & 1 \\
\hline Pancreas CA & 9 & $7.7 \%$ & 5 & 3 & 2 & 1 \\
\hline Squamous carcinoma & 9 & $7.7 \%$ & 5 & 1 & 0 & 0 \\
\hline Prostate CA & 9 & $7.7 \%$ & 3 & 0 & 0 & 0 \\
\hline Anal canal CA & 6 & $5.1 \%$ & 1 & 2 & 0 & 0 \\
\hline Germ cell tumor & 6 & $5.1 \%$ & 2 & 2 & 1 & 0 \\
\hline Oral cavity & 4 & $3.4 \%$ & 2 & 0 & 0 & 0 \\
\hline Uterus sarcoma & 4 & $3.4 \%$ & 2 & 0 & 0 & 0 \\
\hline Urinary bladder CA & 3 & $2.6 \%$ & 1 & 2 & 0 & 0 \\
\hline Glioblastoma CA & 2 & $1.7 \%$ & 1 & 0 & 0 & 0 \\
\hline Ewing sarcoma & 1 & $0.9 \%$ & 0 & 1 & 1 & 0 \\
\hline
\end{tabular}

of our choosing [42-44]. The results reported so far, including the present study, show varied incidences of MSI and LOH in many types of cancers [45-47]. Our investigation revealed $\mathrm{MSI}$ and $\mathrm{LOH}$ mutations to occur in $7 / 10$ markers studied, a total MSI incidence of $66.7 \%$ among mixed origin cancer patients represents a significant level of chemotherapy related genetic instability.

MSI and LOH events appeared to be most prevalent in the Tp53-Alu marker, although Mfd41 and APC also exhibited significant incidences of MSI and LOH (Table 2). These results do not seem to be due to spontaneous occurrence, given that the individuals in the reference group did not show any changes in these microsatellite sequences. In addition, MSI and LOH events significantly correlated with low expression of MMR proteins (Table 3). These findings support the hypothesis that malfunctions of the MMR, along with the error-prone nature of microsatellite sequences, contributes to the development of MSI and LOH. Previous studies report that chemotherapy-induced MSI and LOH triggers secondary AML and myelodysplastic syndrome in $1-2 \%$ of cancer patients within a few months to several years after completion of chemotherapy [1-3,7]. Recent studies with larger cohorts and broader selection of tumor types suggest an even higher incidence (up to 5\%) of secondary tumors [4]. Additionally, secondary AML is believed to occur in $10-30 \%$ of all diagnosed cases of AML [3]. The elevated incidence of secondary AML in more recent studies could be due to longer survival times for chemotherapy treated patients, and the administration of new generations of DNA-damaging chemotherapies (particularly alkylating agents and platinum-based anti-cancer drugs). It is not yet fully understood if somatic mutations predispose carriers to specific tumors, or at minimum, mediate the development of resistant phenotypes of cancer.

In reviewing the incidence of MSI and $\mathrm{LOH}$ in different solid tumors (Table 4), we observed that gastric, lung, ovarian, nasopharyngeal, pancreatic, squamous cell carcinoma, and prostate cancers (which together form $78 \%$ of our cohort) showed varied incidence of MSI. Incidence of MSI ranged from $33.3 \%$ in prostate to $83-87 \%$ in lung, pancreatic and gastric cancers, and showed a strong correlation with deficiencies of MMR proteins. Follow-up studies for up to 52 months showed that undesirable effects of chemotherapy were detected in those patients who previously were found to harbor MSI and LOH mutations and show MMR deficiency. These effects are presented clinically as resistance to chemotherapy regimen and recurrence of the primary disease in 15 patients (12.8\%), or developing secondary cancers or myelodysplastic syndrome in 4 patients (3.4\%; Table 4). Previous studies have shown that although immunohistochemistry has an advantage over MSI analysis in identifying MMR deficient samples, it is incapable of distinguishing MMR proteins with impaired function from normally functioning proteins $[48,49]$. The four major MMR proteins (hMLH1, hMSH2, hMSH6, and hPMS2) are not equally engaged in the repair of different length microsatellite instability. hMSH6 is involved primarily in the repair of single base-base mismatches or single base deletions/insertions, but appears to have no functional role in the repair of dinucleotides or longer mismatches [49]. This variety in MMR protein roles highlights the necessity of combining microsatellite instability analysis with MMR proteins immunohistochemistry in screening cancer patients.

LOH in tumor suppressor inhibitor of growth 1 (ING1) is associated with carcinogenesis in human non-small cell 
lung cancer [50], and deletion in the neurofibromin 1 (NF1) gene promotes formation of malignant melanoma [51]. Our results add to this evidence by demonstrating somatic mutations leading to $\mathrm{LOH}$ in another tumor suppressor gene (Tp53-alu, chr. 17p13.1). Another important finding of this study was the MSI and $\mathrm{LOH}$ observed in $A P C$; $\mathrm{LOH}$ in certain alleles of APC was accompanied with the emergence of a novel allele at this locus. Whereas APC plays a role in hereditary nonpolyposis colorectal cancer (HNPCC) [52], and is methylated in the tumorigenesis of other cancers [53,54], mutated APC may be of value in predicting secondary malignancies if more data are made available about its status during tumorigenesis of secondary cancers.

A murine study designed to assess the profundity and persistence of the genotoxic effects of chemotherapy drugs in current use showed that chemotherapy drugs pose a trans-generational risk manifested in higher mutation rates and genetic instability in the first generation of the treated animals $[33,34]$. These results may justify concerns about similar genetic instabilities in children of anticancer chemotherapy surviving patients.

Insertion/deletion mutations and the error-prone nature of microsatellites are often implicated in the development of chemotherapy-related secondary malignancies. Recent findings suggest an involvement of myeloid/lymphoid or mixed-lineage leukemia rearrangement events as a triggering mechanism that mediates the development of secondary AML after completion of chemotherapy treatment using Etoposide [11], or a combination of Methotrexate, Cisplatin, doxorubicin, and Etoposide [7].

A predictive value for MSI and LOH in HNPCC was determined after use in molecular profiling and survival studies in such patients $[41,55]$. Recent findings support the role of somatic mutations in tumor suppressors in cancers developing resistance to chemotherapies $[56,57]$. This may be explained by emphasizing the mode of action of many chemotherapies; these treatments aim to trigger programmed cell death in cancer cells, a process largely mediated by tumor suppressors like the tumor protein $53(T p 53)$ and retinoblastoma $(R B)$ genes. Analysis of MSI and LOH in sequences linked to these genes is likely to be of predictive value in tumorigenesis that is known to occur through inactivation of these genes. Although our cohort was predominantly younger $(68$ patients less than 51 years of age, see Additional file 2: Figure S2), our results indicate that MSI and LOH increased with age, likely due to the synergistic effect between chemotherapy-induced genetic instability and age-related increased cellular stress.

MSI and LOH play an important role in the early stages of tumorigenesis. The frequency with which MSI and $\mathrm{LOH}$ present as adverse effects of currently used chemotherapy drugs, along with the important role
LOH plays in inactivating tumor suppressor genes, demonstrates the importance of MSI and $\mathrm{LOH}$ as indicators and valuable bio-markers in screening cancer patients after completion of their chemotherapy regimen. Moreover, screening of microsatellite sequences that are directly related to tumor suppressors or are physically adjacent to these genes may aid in the earlier prediction of secondary neoplasm and is likely to provide a better understanding of tumorigenesis, which in turn may lead to more efficient alternative treatments.

\section{Methods}

\section{Study design and chemotherapy regimen}

The inclusion rule applied in this study was that only patients receiving chemotherapy for the first time were selected. Patients with colon or breast cancers and those with family history or evidence of higher tendency to develop tumors were excluded. Peripheral blood was collected for genetic analysis and tumor tissues that were biopsied or resected from patients were retrieved from pathology departments to perform immunohistochemistry testing for the expression of MMR proteins. Followup studies were performed for 48-52 months after completion of the chemotherapy regimen to monitor the presence of clinical complications (especially resistance to chemotherapy, recurrence of primary disease, and/or development of secondary cancers).

Patients were monitored for chemotherapy-related MSI and LOH, MMR expression, and tumor recurrences or development of secondary tumors. Chemotherapy regimens administered in the management of the tumors that were sampled in this study are displayed in Additional file 3: Table S2. Our research conformed to the Helsinki declaration and local legislations, and has been approved by the AlAin Medical District Human Research Ethics Committee at the Faculty of Medicine and Health Sciences, University of United Arab Emirates, under ethical permit no. AAMD/HREC 08/15. All participating patients signed consent forms after receiving a verbal and written information sheet.

\section{Blood samples and cancer tissues collection}

A total of 351 peripheral blood samples were collected from 117 de novo cancer patients with a mean age of 54 years (18-89 years). Sampled tumors included: 20 gastric carcinoma (CA), 19 nasopharyngeal cancer, 13 ovarian cancer, 12 lung cancer, 9 pancreatic CA, 9 prostate CA, 9 squamous cell CA, 6 anal canal cancer, 6 germ cell tumors, 4 oral cavity cancer, 4 uterus sarcoma, 3 urinary bladder CA, 2 glioblastoma, and 1 case of Ewing's sarcoma. Sampling was conducted on three occasions starting at 4-5 weeks prior to the first chemotherapy session (pre-treatment sample) to serve as a baseline, and two consecutive draws at 12-week 
intervals after the first collection. Initial post-treatment samples (post-treatment-1) were used to investigate the presence of MSI and $\mathrm{LOH}$, and second posttreatment samples (post-treatment-2) were used to determine the persistence of the initial findings. One hundred eighty blood samples were collected from 60 healthy individuals who had never reported symptoms relevant to any neoplastic case. Sampling of the reference group followed the same protocol applied to patients. Samples of 196 cancer tissues resected from patients were collected from the pathology department for MMR protein expression analysis using immunohistochemistry.

\section{DNA extraction and $\mathrm{LOH}$ and MSI analysis}

Genomic DNA was extracted from whole blood using 200$\mu \mathrm{l}$ blood DNA kits, on a Biorobot EZ1 workstation (Qiagen Inc, Valencia, California, USA,). DNA yield was quantified using absorbance at $\mathrm{A}_{260}$ on a Beckman Coulter DU 650 spectrophotometer with special applications for nucleic acid quantification (Beckman Coulter Inc, Brea, California, USA). DNA purity, checked on $A_{260} / A_{280}$ absorbance, averaged 1.72 .

Single and multiplex polymerase chain reactions (PCR) were conducted to amplify 10 loci (Bat-40, AFM093xh3, Bat-25, APC, Mfd15, Mfd41, Mfd28, Bat-26, Tp53-Alu and TP53.PCR15) on chromosomes 1, 2, 4, 5, 10, and 17. Fluorescently labeled primers were used to amplify the selected loci as previously described [58], and are detailed in Additional file 3: Table S2. Amplification reactions were conducted in $10 \mu \mathrm{l}$ reaction volume of $1 \times$ Gold Amplitaq Master Mix (Applied Biosystems, Carlsbad, California, USA) with the addition of $80 \mathrm{ng}$ purified genomic DNA, and adjusted to a final primer concentration of $0.4 \mu \mathrm{M}$. Cycling conditions were as follows: initial denaturation at $95^{\circ} \mathrm{C}$ for 5 minutes; 29 cycles of $94^{\circ} \mathrm{C}$ for $45 \mathrm{sec}, 50-62^{\circ} \mathrm{C}$ for $30 \mathrm{sec}$, and $72^{\circ} \mathrm{C}$ for 50 seconds; and a final 50 minute extension at $70^{\circ} \mathrm{C}$. PCR products were denatured in $\mathrm{Hi}-\mathrm{Di}$ formamide, pooled with LIZ 500 GS internal molecular weight control and loaded on an ABI 3130 genetic analyzer (Applied Biosystems, Carlsbad, California, USA). Fragments were measured and compared using GeneMapper software Version 4 (Applied Biosystems, Carlsbad, California, USA). GeneScan data were obtained using a minimum peak detection limit of 50 relative fluorescent units and applying the local Southern size calling method. MSI irregularities were demonstrated by comparisons between the numbers and allele arrangements of pretreatment and post-treatment samples. Specifically, new peak addition or the presence of novel alleles indicated MSI [59], whereas LOH was indicated when the peak height of one of the two heterozygote alleles was reduced by at least 35\% [60,61]. GeneMapper Software Version 4 was used to calculate $\mathrm{LOH}$.

\section{MMR analyses}

Archived tissue samples were available from 101 patients. In three cases, the available tissues were not sufficient for the procedure. Two specimens from each patient were tested for MMR protein expression (pre and post-treatment). The 196 cancer tissues were embedded in paraffin blocks for MMR protein expression analysis. The TP-125 HLX Ultravision Plus Anti-Polyvalent HRP detection system (Lab Vision, Fremont, California, USA) using specific monoclonal antibodies for hMLH1, hMSH2, hMSH6, hPMS2 and P53 (Cell Marque, Rocklin, California , USA, California) was used in the staining procedure. Results were marked as positive when $10 \%$ or more of cells stained positively (nuclear stain). Healthy tissue from each patient and the standard controls supplied by the manufacturer were used as internal controls.

\section{Statistical analyses}

Confidence intervals were calculated at the $95 \%$ and $99 \%$ levels. Fisher's exact test and Chi Square were used for statistical analyses with the SPSS statistical analysis package. Additionally, an inter-rater reliability test using Cohen's kappa coefficient was used to measure correlation between the MSI and $\mathrm{LOH}$ results and low MMR protein expression [62].

\section{Additional files}

Additional file 1: Figure S1. Emergence of a novel allele of 162

nucleotides following the loss of heterozygosity in alleles 109 and 118 of APC.

Additional file 2: Figure S2. Positive correlation between rates of MSI and $\mathrm{LOH}$ and the patient's age. As patient's age increases, the incidence of MSI and LOH appears to increase.

Additional file 3: Table S1. Frequently used chemotherapy treatments in managing the sampled solid tumors in the current study. Table S2. The specific characteristics of the analyzed microsatellite markers.

\section{Abbreviations \\ AML: Acute myeloid leukemia; HNPCC: Hereditary nonpolyposis colorectal carcinoma; hMLH1: Human mutL homolog 1; hMSH2: Human mutS homolog 2; hMSH6: Human mutS homolog 6; hPMS1: Human post-meiotic segregation increased 1; hPMS2: Human post-meiotic segregation increased 2; LOH: Loss of heterozygosity; MMR: Mismatch repair; MSI: Microsatellite instability; NCl: National Cancer Institute; NER: Nucleotide excision repair; NIN: Nucleotide instability; PCR: Polymerase chain reaction; p53: p53 tumor suppressor protein.}

\section{Competing interests}

The authors declare that they have no competing interest.

\section{Authors' contribution}

NK, study design, carried out the molecular genetic studies, analyzed the results, and scripted the paper. MAK participated in the study design and reviewed written material. MMA carried out the immunohistochemistry assays. SH selected study candidates and performed clinical follow up for the period of the study. UR study design, analyzed and reviewed the results. All authors read and approved the final manuscript.

\section{Acknowledgements}

We thank Professor Mohamed Yahia El-Bassiouni for performing statistical analysis for the data of this study, and appreciate the help provided by the 
nursing staff in the oncology department, and hematology and pathology laboratories personnel at Tawam hospital.

\section{Source of funding}

Grant support: Sven and Lilly Lawski Foundation.

\section{Author details}

'Department of Molecular Biosciences, the Wenner-Gren Institute (MBW), Stockholm University, SE-106 91 Stockholm, Sweden. ²Department of Genetics Research, Management of Natural Conservations, AlAin City, UAE. ${ }^{3}$ Department of Oncology and Hematology, Tawam Hospital, AIAin City, UAE. ${ }^{4}$ Department of Pathology, University of Utah, Salt Lake City, Utah 84112 , USA

Received: 14 April 2014 Accepted: 27 October 2014

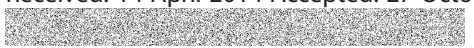

\section{References}

1. Bernard-Marty C, Mano M, Paesmans M, Accettura C, Munoz-Bermeo R, Richard T, Kleiber K, Cardoso F, Lobelle JP, Larsimont D, Piccart MJ, Di Leo A: Second malignancies following adjuvant chemotherapy: 6-year results from a Belgian randomized study comparing cyclophosphamide, methotrexate and 5-fluorouracil (CMF) with an anthracycline-based regimen in adjuvant treatment of node-positive breast cancer patients. Ann Oncol 2003, 14(5):693-698.

2. Krishnan B, Morgan GJ: Non-Hodgkin lymphoma secondary to cancer chemotherapy. Cancer Epidemiol Biomarkers Prev 2007, 16(3):377-380.

3. Leone G, Mele L, Pulsoni A, Equitani F, Pagano L: The incidence of secondary leukemias. Haematologica 1999, 84(10):937-945.

4. Leone G, Pagano L, Ben-Yehuda D, Voso MT: Therapy-related leukemia and myelodysplasia: susceptibility and incidence. Haematologica 2007 92(10):1389-1398.

5. Grunwald HW, Rosner F: Acute myeloid leukemia following treatment of Hodgkin's disease: a review. Cancer 1982, 50(4):676-683.

6. Pedersen-Bjergaard J, Larsen SO: Incidence of acute nonlymphocytic leukemia, preleukemia, and acute myeloproliferative syndrome up to 10 years after treatment of Hodgkin's disease. N Engl J Med 1982, 307(16):965-971.

7. Bielorai B, Meyer C, Trakhtenbrot L, Golan H, Rozner E, Amariglio N, Izraeli S, Marschalek $R$, Toren A: Therapy-related acute myeloid leukemia with $\mathrm{t}(2 ; 11)(\mathrm{q} 37 ; \mathrm{q} 23)$ after treatment for osteosarcoma. Cancer Genet Cytogenet 2010, 203(2):288-291.

8. Campone $\mathrm{M}$, Roche $\mathrm{H}$, Kerbrat $\mathrm{P}$, Bonneterre J, Romestaing $\mathrm{P}$, Fargeot $\mathrm{P}$, Namer M, Monnier A, Montcuquet P, Goudier MJ, Fumoleau P: Secondary leukemia after epirubicin-based adjuvant chemotherapy in operable breast cancer patients: 16 years experience of the French Adjuvant Study Group. Ann Oncol 2005, 16(8):1343-1351.

9. Chaplain G, Milan C, Sgro C, Carli PM, Bonithon-Kopp C: Increased risk of acute leukemia after adjuvant chemotherapy for breast cancer: a population-based study. J Clin Oncol 2000, 18(15):2836-2842.

10. Kirova YM, De Rycke Y, Gambotti L, Pierga JY, Asselain B, Fourquet A: Second malignancies after breast cancer: the impact of different treatment modalities. $\mathrm{Br} J$ Cancer 2008, 98(5):870-874.

11. Libura J, Slater DJ, Felix CA, Richardson C: Therapy-related acute myeloid leukemia-like MLL rearrangements are induced by etoposide in primary human CD34+ cells and remain stable after clonal expansion. Blood 2005, 105(5):2124-2131.

12. Le H, Singh S, Shih SJ, Du N, Schnyder S, Loredo GA, Bien C, Michaelis L, Toor A, Diaz MO, Vaughan AT: Rearrangements of the MLL gene are influenced by DNA secondary structure, potentially mediated by topoisomerase II binding. Genes Chromosomes Cancer 2009, 48(9):806-815.

13. Kumar D, Abdulovic AL, Viberg J, Nilsson AK, Kunkel TA, Chabes A: Mechanisms of mutagenesis in vivo due to imbalanced dNTP pools. Nucleic Acids Res 2010, 39:4949-4954.

14. Gulcher J: Microsatellite markers for linkage and association studies. Cold Spring Harb Protoc 2012, 2012(4):425-432.

15. Ellegren $\mathrm{H}$ : Microsatellites: simple sequences with complex evolution. Nat Rev Genet 2004, 5(6):435-445.

16. Selkoe KA, Toonen RJ: Microsatellites for ecologists: a practical guide to using and evaluating microsatellite markers. Ecol Lett 2006, 9(5):615-629.
17. Goldstein DB, Roemer GW, Smith DA, Reich DE, Bergman A, Wayne RK: The Use of Microsatellite Variation to Infer Population Structureand Demographic History in a Natural Model System. Genetics 1999, 151:797-801.

18. McMurray CT: Mechanisms of trinucleotide repeat instability during human development. Nat Rev Genet 2010, 11(11):786-799.

19. La Spada AR, Richards RI, Wieringa B: Dynamic mutations on the move in Banff. Nat Genet 2004, 36(7):667-670.

20. Balaresque P, Bowden GR, Parkin EJ, Omran GA, Heyer E, Quintana-Murci L Roewer L, Stoneking M, Nasidze I, Carvalho-Silva DR, Tyler-Smith C, de Knijff $P$, Jobling MA: Dynamic nature of the proximal AZFc region of the human $Y$ chromosome: multiple independent deletion and duplication events revealed by microsatellite analysis. Hum Mutat 2008, 29(10):1171-1180.

21. Choi BO, Kim J, Lee KL, Yu JS, Hwang JH, Chung KW: Rapid diagnosis of CMT1A duplications and HNPP deletions by multiplex microsatellite PCR. Mol Cells 2007, 23(1):39-48.

22. Champeme MH, Bieche I, Beuzelin M, Lidereau R: Loss of heterozygosity on 7q31 occurs early during breast tumorigenesis. Genes Chromosomes Cancer 1995, 12(4):304-306.

23. Velickovic M, Delahunt B, Storkel S, Grebem SK: VHL and FHIT locus loss of heterozygosity is common in all renal cancer morphotypes but differs in pattern and prognostic significance. Cancer Res 2001, 61(12):4815-4819.

24. Smith AP, Henze M, Lee JA, Osborn KG, Keck JM, Tedesco D, Bortner DM, Rosenberg MP, Reed SI: Deregulated cyclin E promotes p53 loss of heterozygosity and tumorigenesis in the mouse mammary gland. Oncogene 2006, 25(55):7245-7259.

25. Akoum R, Ghaoui A, Brihi E, Ghabash M, Hajjar N: Early-onset breast cancer in a Lebanese family with Lynch syndrome due to MSH2 gene mutation. Hered Cancer Clin Pract 2009, 7(1):10.

26. Topping RP, Wilkinson JC, Scarpinato KD: Mismatch repair protein deficiency compromises cisplatin-induced apoptotic signaling. J Biol Chem 2009, 284(21):14029-14039.

27. Larson ED, Maizels N: Transcription-coupled mutagenesis by the DNA deaminase AID. Genome Biol 2004, 5(3):211.

28. Shimodaira H, Yoshioka-Yamashita A, Kolodner RD, Wang JY: Interaction of mismatch repair protein PMS2 and the p53-related transcription factor p73 in apoptosis response to cisplatin. Proc Natl Acad Sci U S A 2003, 100(5):2420-2425.

29. Albrechtsen N, Dornreiter I, Grosse F, Kim E, Wiesmuller L, Deppert W: Maintenance of genomic integrity by $\mathrm{p} 53$ : complementary roles for activated and non-activated p53. Oncogene 1999, 18(53):7706-7717.

30. Geske FJ, Nelson AC, Lieberman R, Strange R, Sun T, Gerschenson LE: DNA repair is activated in early stages of $\mathrm{p} 53$-induced apoptosis. Cell Death Differ 2000, 7(4):393-401.

31. Zhu L, Ba WG: p53: Structure, Function and Therapeutic Applications. J Cancer Mol 2006, 2:141-153.

32. Herschkowitz II, He X, Fan C, Perou CM: The functional loss of the retinoblastoma tumour suppressor is a common event in basal-like and luminal B breast carcinomas. Breast Cancer Res 2008, 10(5):R75.

33. Abouzeid Ali HE, Barber RC, Dubrova YE: The effects of maternal irradiation during adulthood on mutation induction and transgenerational instability in mice. Mutat Res 2012, 732(1-2):21-25.

34. Glen CD, Dubrova YE: Exposure to anticancer drugs can result in transgenerational genomic instability in mice. Proc Natl Acad Sci U S A 2012, 109(8):2984-2988.

35. Pinto JL, Fonseca FL, Marsicano SR, Delgado PO, Sant'anna AV, Coelho PG, Maeda P, Del Giglio A: Systemic chemotherapy-induced microsatellite instability in the mononuclear cell fraction of women with breast cancer can be reproduced in vitro and abrogated by amifostine. J Pharmacy Pharmacol 2010, 62(7):931-934.

36. Fonseca FL, Sant Ana AV, Bendit I, Arias V, Costa LJ, Pinhal AA, del Giglio A Systemic chemotherapy induces microsatellite instability in the peripheral blood mononuclear cells of breast cancer patients. Breast Cancer Res 2005, 7(1):R28-R32.

37. Kamat N, Khidhir MA, Jaloudi M, Hussain S, Alashari MM, Al Qawasmeh $\mathrm{KH}$, Rannug $\mathrm{U}$ : High incidence of microsatellite instability and loss of heterozygosity in three loci in breast cancer patients receiving chemotherapy: a prospective study. BMC Cancer 2012, 12:373.

38. Ribic CM, Sargent DJ, Moore MJ, Thibodeau SN, French AJ, Goldberg RM, Hamilton SR, Laurent-Puig P, Gryfe R, Shepherd LE, Tu D, Redston M, Gallinger S: Tumor microsatellite-instability status as a predictor of 
benefit from fluorouracil-based adjuvant chemotherapy for colon cancer. N Engl J Med 2003, 349(3):247-257.

39. Ng K, Schrag D: Microsatellite instability and adjuvant fluorouracil chemotherapy: a mismatch? J Clin Oncol 2010, 28(20):3207-3210.

40. Watanabe T, Kanazawa T, Kazama Y, Tanaka J, Tanaka T, Ishihara S, Nagawa H, Benatti P, Ponz de Leon M, Gafa R, Lanza G, Barana D, Oliani C: Adjuvant chemotherapy in colorectal cancer patients with microsatellite instability. Clin Cancer Res 2006, 12(12):3866-3867. author reply 3867.

41. EGAPP: Recommendations from the EGAPP Working Group: genetic testing strategies in newly diagnosed individuals with colorectal cancer aimed at reducing morbidity and mortality from Lynch syndrome in relatives. Genet Med 2009, 11(1):35-41.

42. Ogino S, Goel A: Molecular classification and correlates in colorectal cancer. J Mol Diagn 2008, 10(1):13-27.

43. An C, Choi IS, Yao JC, Worah S, Xie K, Mansfield PF, Ajani JA, Rashid A, Hamilton SR, Wu TT: Prognostic significance of $\mathrm{CpG}$ island methylator phenotype and microsatellite instability in gastric carcinoma. Clin Cancer Res 2005, 11(2 Pt 1):656-663.

44. Mead L, Jenkins MA, Young J, Royce SG, Smith L, St John DJ, Macrae F, Giles GG, Hopper JL, Southey MC: Microsatellite instability markers for identifying early-onset colorectal cancers caused by germ-line mutations in DNA mismatch repair genes. Clin Cancer Res 2007, 13(10):2865-2869.

45. Wagner DG, Gatalica Z, Lynch HT, Kohl S, Johansson SL, Lele SM: Neuroendocrine-type prostatic adenocarcinoma with microsatellite instability in a patient with lynch syndrome. Int I Surg Pathol 2010 18(6):550-553

46. Giunti L, Cetica V, Ricci U, Giglio S, Sardi I, Paglierani M, Andreucci E, Sanzo M, Forni M, Buccoliero AM, Genitori L, Genuardi M: Type A microsatellite instability in pediatric gliomas as an indicator of Turcot syndrome. Eur $J$ Hum Genet 2009, 17(7):919-927.

47. Clarke B, Gordon M, Moodley M, Naidoo R, Chetty R: Microsatellite analysis of early stage (la-llb) uterine cervical squamous carcinoma. Int I Surg Pathol 2003, 11(4):253-260.

48. Heo M, Shakhnovich El: Interplay between pleiotropy and secondary selection determines rise and fall of mutators in stress response. PLOS Comput Biol 2010, 6(3):e1000710.

49. You JF, Buhard O, Ligtenberg MJ, Kets CM, Niessen RC, Hofstra RM, Wagner A, Dinjens WN, Colas C, Lascols O, Collura A, Flejou JF, Duval A, Hamelin R: Tumours with loss of MSH6 expression are MSI-H when screened with a pentaplex of five mononucleotide repeats. Br J Cancer 2010, 103(12):1840-1845.

50. Luo ZG, Tang H, Li B, Zhu Z, Ni CR, Zhu MH: Genetic alterations of tumor suppressor ING1 in human non-small cell lung cancer. Oncol Rep 2011, 25:1073-1081.

51. Rubben A, Bausch B, Nikkels A: Somatic deletion of the NF1 gene in a neurofibromatosis type 1-associated malignant melanoma demonstrated by digital PCR. Mol Cancer 2006, 5:36.

52. Narayan S, Roy D: Role of APC and DNA mismatch repair genes in the development of colorectal cancers. Mol Cancer 2003, 2:41.

53. Henrique R, Ribeiro FR, Fonseca D, Hoque MO, Carvalho AL, Costa VL, Pinto M, Oliveira J, Teixeira MR, Sidransky D, Jerónimo C: High promoter methylation levels of APC predict poor prognosis in sextant biopsies from prostate cancer patients. Clin Cancer Res 2007, 13(20):6122-6129.

54. Tsuchiya T, Tamura G, Sato K, Endoh Y, Sakata K, Jin Z, Motoyama T, Usuba O, Kimura W, Nishizuka S, Wilson KT, James SP, Yin J, Fleisher AS, Zou T, Silverberg SG, Kong D, Meltzer SJ: Distinct methylation patterns of two APC gene promoters in normal and cancerous gastric epithelia. Oncogene 2000, 19(32):3642-3646.

55. Umar A, Boland CR, Terdiman JP, Syngal S, de la Chapelle A, Ruschoff J, Fishel R, Lindor NM, Burgart LJ, Hamelin R, Hamilton SR, Hiatt RA, Jass J, Lindblom A, Lynch HT, Peltomaki P, Ramsey SD, Rodriguez-Bigas MA, Vasen HF, Hawk ET, Barrett JC, Freedman AN, Srivastava S: Revised Bethesda Guidelines for hereditary nonpolyposis colorectal cancer (Lynch syndrome) and microsatellite instability. J Natl Cancer Inst 2004, 96(4):261-268.

56. Augustine CK, Yoo JS, Potti A, Yoshimoto Y, Zipfel PA, Friedman HS, Nevins JR, Ali-Osman F, Tyler DS: Genomic and molecular profiling predicts response to temozolomide in melanoma. Clin Cancer Res 2009, 15(2):502-510.

57. Honecker F, Wermann H, Mayer F, Gillis AJ, Stoop H, van Gurp RJ, Oechsle K, Steyerberg E, Hartmann JT, Dinjens WN, Oosterhuis JW, Bokemeyer C, Looijenga LH: Microsatellite instability, mismatch repair deficiency, and BRAF mutation in treatment-resistant germ cell tumors. J Clin Oncol 2009, 27(13):2129-2136.
58. Dietmaier W, Wallinger S, Bocker T, Kullmann F, Fishel R, Ruschoff J: Diagnostic microsatellite instability: definition and correlation with mismatch repair protein expression. Cancer Res 1997, 57(21):4749-4756.

59. Siah SP, Quinn DM, Bennett GD, Casey G, Flower RL, Suthers G, Rudzki Z: Microsatellite instability markers in breast cancer: a review and study showing MSI was not detected at 'BAT 25' and 'BAT 26' microsatellite markers in early-onset breast cancer. Breast Cancer Res Treat 2000, 60(2):135-142

60. Powierska-Czarny J, Miscicka-Sliwka D, Czarny J, Grzybowski T, Wozniak M, Drewa G, Czechowicz W, Sir J: Analysis of microsatellite instability and loss of heterozygosity in breast cancer with the use of a well characterized multiplex system. Acta Biochim Pol 2003, 50(4):1195-1203.

61. Green MR, Jardine P, Wood P, Wellwood J, Lea RA, Marlton P, Griffiths LR: A new method to detect loss of heterozygosity using cohort heterozygosity comparisons. BMC Cancer 2010, 10:195.

62. Agresti A: Categorical Data Analysis. 2nd edition. New Jersey: Wiley; 2002.

\section{doi:10.1186/s12935-014-0118-4}

Cite this article as: Kamat et al.: Chemotherapy induced microsatellite instability and loss of heterozygosity in chromosomes 2, 5, 10, and 17 in solid tumor patients. Cancer Cell International 2014 14:118.

\section{Submit your next manuscript to BioMed Central and take full advantage of:}

- Convenient online submission

- Thorough peer review

- No space constraints or color figure charges

- Immediate publication on acceptance

- Inclusion in PubMed, CAS, Scopus and Google Scholar

- Research which is freely available for redistribution

Submit your manuscript at www.biomedcentral.com/submit
C Biomed Central 